\title{
Restrictions on genitive subjects in Kazakh relative clauses Eszter Ótott-Kovács*
}

\begin{abstract}
This article investigates two RC subject case marking strategies in Kazakh based on novel data coming from the author's fieldwork. The two strategies are the NOM-subject strategy, where the RC subject is nominative and there is no agreement marking with it, and the GEN-subject strategy, where the RC subject is genitive and the agreement with it is marked, seemingly non-locally, on the noun phrase modified by the RC. The paper's goal is to offer new empirical data on the characteristics and restrictions on the GEN-subject strategy: the GEN-DP is RC external and the same restrictions apply to it as to possessors, for this reason the paper argues that the GENDP is situated (and gets case) in the possessor position and it is not assigned genitive case within the RC. Thus, the seemingly non-local Agree relation can be accounted if the GEN-DP is in clause-external possessor position.
\end{abstract}

Keywords. Kazakh; Turkic; relative clauses; non-finite clauses; non-local agreement; genitive subject; possessor

1. Introduction. Kazakh has two subject case assignment and subject agreement marking strategies in non-subject relative clauses (henceforth, RCs). ${ }^{1}{ }^{2}$ The RC subject can be in the nominative case and there is no overt subject agreement suffix. The Kazakh example in (1) illustrates this strategy, which I refer to as "NOM-subject strategy." Here, the subject Ajnur is nominative and there is no overt suffix indicating agreement with it.

[Ajnur-Ø radio-dan esti-gen] œlen

[Ainur-NOM radio-ABL hear-NF] poem $^{3}$

'the poem that Ainur heard on the radio'

The second strategy is to mark the subject with the genitive -NIy and to indicate subject agreement on the modified noun phrase. ${ }^{4}$ In the Kazakh example in (2), the RC subject Ajnur is

\footnotetext{
* I am very grateful for all my consultants for their generosity, help and patience. I'm deeply indebted to Saule Tazhibaeva (L.N. Gumilyov Eurasian National University) for introducing me not only to many of my consultants but also for welcoming me in her home. I owe many thanks to Miloje Despić, John Whitman, John Bowers, two anonymous reviewers, and the audiences of WAFL15 and $\mathrm{Tu}+5$ conferences for their comments and discussions. All errors are my own.

Author: Eszter Ótott-Kovács, Cornell University (eo264@cornell.edu).

${ }^{1}$ Kazakh is a Kipchak Turkic language spoken in Kazakhstan and in the neighboring countries (Xinjiang Province of China, Western Mongolia, Northern Kyrgyzstan and Uzbekistan, in Astrakhan, Orenburg, Omsk, Saratov Oblasts in the Russian Federation). The paper is based on Kazakh as spoken in Kazakhstan.

${ }^{2}$ Relative clauses in Kazakh come before the modified noun phrase, and the RC predicate is non-finite. There is a gap in the RC corresponding to the modified noun phrase; this gap cannot be filled with any overt element. The exponents of the RC head are -GAn (-gan, -gen, -kan, -ken) and -j/AtIn (-jatun, -jetin, -atun, -etin); the distinction between $-G A n$ and $-j / A t I n$ is related to Aspect.

${ }^{3}$ Glosses: $\mathrm{ABL}=$ ablative, $\mathrm{ACC}=$ accusative, $\mathrm{ADJ}=$ adjectival suffix, $\mathrm{AUX}=$ auxiliary, $\mathrm{DAT}=$ dative, $\mathrm{GEN}=\mathrm{genitive}$, $\mathrm{IP}=-(I) p$ suffix that is part of an auxiliary construction, $\mathrm{LOC}=$ locative, $\mathrm{NEG}=$ negative, $\mathrm{NF}=$ non-finite clausal marker (e.g., relative clause head, complement clause head), NOM = nominative, $\mathrm{PL}=$ plural, $\mathrm{POSS}=$ possessive, $\mathrm{PRF}$ $=$ perfect, $\mathrm{PRS}=$ present, $\mathrm{PST}=$ past, $\mathrm{SG}=$ singular.

${ }^{4}$ Capitalization in suffixes indicates morpho-phonological alternation where the marked sounds undergo change.

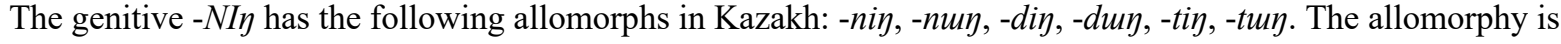
determined by the phonological form of the stem.
} 
in the genitive and the agreement with Ajnur is marked on the modified noun phrase $x$ eley 'poem'. I call this "GEN-subject strategy."

(2) [Ajnur-dum radio-dan esti-gen] œlen-i

[Ainur-GEN radio-ABL hear-NF] poem-3POSS

'the poem that Ainur heard on the radio'

Unlike in Turkish, it is ill-formed in Kazakh to mark the RC subject with genitive and indicate the agreement on the RC predicate, illustrated in (3). ${ }^{6}$

*[Ajnur-duy radio-dan esti-gen-i] œley

[Ainur-GEN radio-ABL hear-NF-3POSS] poem

Intended: 'the poem that Ainur heard on the radio'

The GEN-subject strategy has attracted a great deal of attention in the linguistic literature because it seemingly violates locality principles of agreement and case assignment. In (2), the RC subject Ajnur is not contained in the same local domain as oeley 'poem', with which it establishes Agrees and which assigns case to it under Agree (Chomsky 1998, 2001 and subsequent work). That is, the subject case assignment and agreement appear to be non-local in the GEN-subject strategy, a theoretically unexpected phenomenon. Several Turkic languages are known to have seemingly non-local agreement and subject case assignment in relative clauses, and the topic has been discussed extensively. ${ }^{7}$ A non-exhaustive list of these Turkic languages and some references are: Sakha (Baker \& Vinokurova 2010), Uyghur (Csató \& Uchturpani 2010, Asarina 2010), Kyrgyz (Laszakovits 2018, 2019a, 2019b), also more generally on Uyghur, Kazakh, Kyrgyz and Sakha (Kornfilt 2005, 2008, 2015) and more recently on Kyrgyz and Sakha (Satık 2020).

While smaller details differ across analyses, the field's knowledge in the analysis of GENsubject RCs has been dominated by Kornfilt (2008 and her subsequent work). Kornfilt (2008, 2015) contrasts the Kazakh/Kyrgyz/Uyghur/Sakha agreement and subject case assignment patterns in RCs with Turkish. In Turkish relative clauses, the subject, as long as it can be marked with genitive, is always genitive, and the subject agreement is indicated on the RC predicate. ${ }^{8}$ Kornfilt argues that Turkish RCs are CPs, and therefore agreement cannot be located outside of the clause, i.e., on the modified noun phrase, because it would be a violation of locality.

Kazakh, Kyrgyz, Uyghur and Sakha RCs are argued to be smaller than CPs, thus not phases. ${ }^{9}$ Since they are not phases, their constituents can be reached by matrix probes, such as by

\footnotetext{
${ }^{5}$ The agreement suffixes in this construction are morphologically the same as possessive suffixes used to mark the possessee in "regular" possessive constructions. For this reason, I gloss these agreement suffixes as POSs (= possessive suffixes).

${ }^{6}$ This is illustrated by the following Turkish sentence:

(i) [Aynur-un radyo-dan duy-duğ-u] şiir (Turkish)

[Ainur-GEN radio-ABL hear-NF-3SG.POSS] poem

'the poem that Ainur heard on the radio'

${ }^{7}$ I shall also mention that some Mongolic languages also have genitive RC subjects and agreement on the modified noun phrase. In fact, Hale's (2002) papers on Dagur (Mongolic) were the first studies that drew attention to these constructions, and have been followed by studies on several other languages. I will not discuss the Mongolic data in this paper, but I want to note that in several respects they are different from the Turkic data.

${ }^{8}$ The claim has been made in Turkish linguistics that the genitive can only be marked on specific noun phrases; i.e., non-specific indefinites cannot be genitive-marked (see e.g., Öztürk 2005).

${ }^{9}$ Asarina (2010) proposes a similar approach but she argues that the RCs are full CPs. Her analysis makes use of the weakened version of Chomsky's (2001) PIC.
} 
the probe on the DP projection of the modified noun phrase. The D head of the modified noun phrase searches the accessible domain for an eligible goal to agree with and to assign the genitive. Since the RC is not a phase, its subject is contained in the search domain, and consequently it can establish Agree with the D head of the modified noun phrase and get genitive under Agree. The tree in (4) illustrates the syntactic structure of this configuration.

(4) "GEN-DP inside the RC” approach

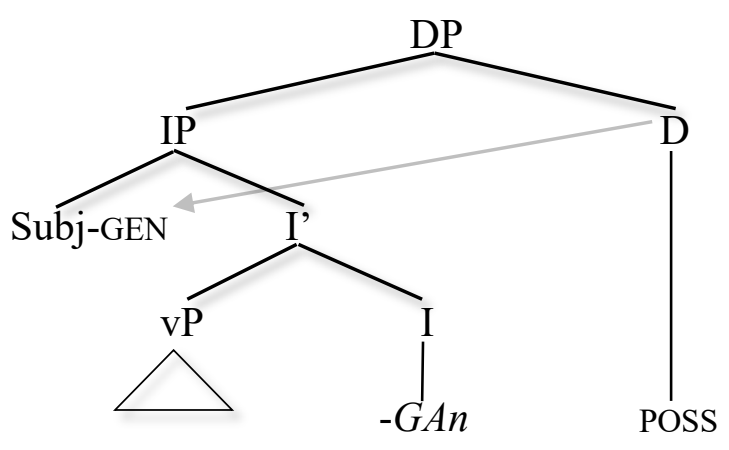

Laszakovits $(2018,2019$ a) further elaborates on this analysis: she proposes a way to account for both the NOM-subject and the GEN-subject patterns. ${ }^{10}$ In her analysis, Asp ${ }^{\circ}$ and $\mathrm{D}^{\mathrm{o}}$ are phase heads (indicated by circles in the tree below). Nominative subjects are claimed to remain inside vP (or in a verbal projection contained in AspP), and they are not accessible for D since they are contained in AspP, which is a phase. In contrast, genitive-marked subjects raise out of vP to Spec,AspP, where they are accessible for outside probes. The D projection of the modified noun phrase probes and finds this noun phrase in Spec,AspP, establishes Agree and assigns genitive to it.

(5) Laszakovits's (2018, 2019a) analysis of genitive and nominative case assignment

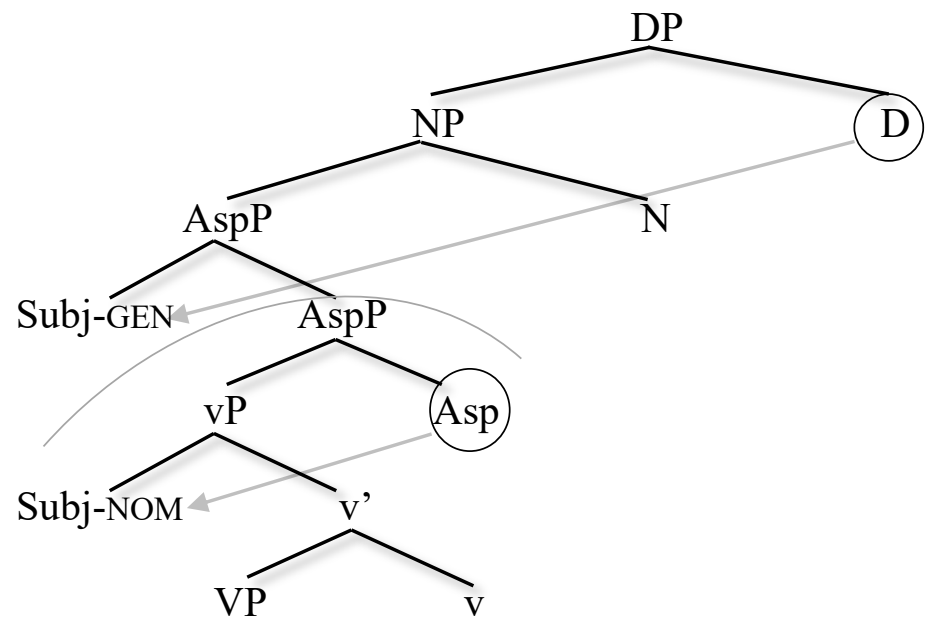

\footnotetext{
${ }^{10}$ Laszakovits (2019b) presents a different analysis based on new Kyrgyz data. In the 2019b analysis she proposes that the genitive RC "subject" is in fact in the possessor position. This most recent account of hers is similar to what the present paper proposes. I reference her previous work here as a possible implementation of the "GEN-DP inside the RC" account but with the caveat that she herself abandoned this approach.
} 
In short, this family of approaches, which I refer to as "GEN-DP inside the RC" approach, takes the GEN-RC subject to be relative clause internal, and they maintain that the genitive DP is not in any way associated with the possessor position, and that genitive is assigned within the RC by the RC-external $\mathrm{D}$ head. The goal of this paper is to present new data on the characteristics and restrictions on the GEN-subject strategy, to shed new light on the syntactic structure of these RCs. Based on novel data, presented in sections 3.2-3.5, I show that the genitive-DP patterns with possessors and using NPI-licensing data we can show that it is in a RC-external position. This leads me to argue that the genitive-DP is in the possessor position, although I won't be able to discuss in this paper if it moves there or if it is base-generated. The tree representation of the proposed syntactic structure is given below.

(6) Proposed syntactic structure for the GEN-subject strategy

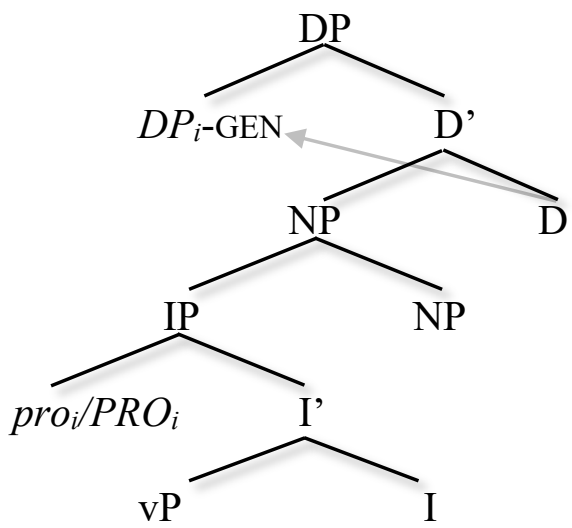

The paper's main focus is to present new empirical data on Kazakh GEN-subject RC strategy, its characteristics and restrictions. Due to space limitation, the present paper does not investigate other Turkic or non-Turkic languages that have similar RC strategies, along with some other related phenomena, such as adverb placement (Kornfilt 2008 and subsequent work), which are also crucial to understand the syntax of Kazakh RCs. These will be dealt with in a future paper (in preparation).

2. Data. The Kazakh data presented in the paper come from my elicitations with native speaker consultants. I did a preliminary study with five native speakers, four of them were living in Ithaca, NY and one of them in Hungary at the time. ${ }^{11}$ Based on these findings, I conducted further elicitations and grammaticality judgement tasks with consultants in Kazakhstan. As Kazakh language skills vary among the Kazakhstani population, I made a point of seeking out consultants who got their (at least, primary) education in Kazakh and use Kazakh with regularity in their daily lives. ${ }^{12}$ I worked with seven consultants, five of them reside in Taraz (Southern Kazakhstan), and two of them are from Western Kazakhstan. The data presented in the paper comes from my fieldwork in Kazakhstan, but it is in accordance with the findings of my preliminary study. Most of the examples I present here were accepted unanimously by the consultants; where it is not the case, I make a notation.

\footnotetext{
${ }^{11}$ My consultants are from Pavlodar, Öskemen, Nur-Sultan (Astana), Almaty, Taldykorgan.

${ }^{12}$ Many Kazakhstanis, especially in urban settings, attend schools where the instruction is solely in Russian with only a few Kazakh classes per week.
} 
3. Properties of the GEN-subject strategy. Before I turn to the discussion of GEN-subject strategy, I shall emphasize that my findings show that there are no restrictions on the NOMsubject strategy; data will always be provided but not discussed in great length, as I am focusing on the GEN-subject strategy. The following subsections present novel data that show that the GEN-DP must be situated in the RC-external possessor position.

3.1 POSSESSORS AND GEN-RC SUBJECTS CANNOT CO-OCCUR. It has long been noticed in the literature that possessors and genitive relative clause subjects cannot co-occur (e.g., Kornfilt 2009). An illustrative example is offered in (7).

(7) *Abaj-dur [Ajnur-dury radio-dan esti-gen] œlen-i

Abai-GEN [Ainur-GEN radio-ABL hear-NF] poem-3POsS

Intended: 'Abai's poem that Ainur heard on the radio'

In contrast, the possessor can co-occur with the NOM-subject strategy, as in (8). Notice that the target DP cley 'poem' bears possessive morphology, which is the case in simple possessive constructions, as illustrated in (9). Example (8) indicates that there is no restriction on the cooccurrence of possessor and relative clause.

(8) Abaj-dun [Ajnur- $\varnothing$ radio-dan esti-gen] œlen-i

Abai-GEN [Ainur-NOM radio-ABL hear-NF] poem-3POsS

'Abai's poem that Ainur heard on the radio'

(9) Abaj-dun œlen-i

Abai-GEN POEM-3POSS

'Abai's poem'

The fact that (7) is ill-formed can be explained under both the GEN-DP inside the RC and the GEN-DP as possessor approaches. Both analyses could invoke the so-called Stuttering Prohibition, proposed by Kornfilt (1986) (for a revised version see Tat \& Kornfilt (2018)), which prohibits haplology of morphemes of the same category irrespective of their phonological form. The Stuttering Prohibition accounts for the ungrammaticality of double-possessor constructions such as (10), by disallowing two possessive agreement morphemes after one another; (10) is ungrammatical because the form * suret-i-m 'paining-3POss-1SG.POSs' is banned. ${ }^{13}$ Furthermore, for each possessor, there must be an overt agreement marking morpheme, i.e., deleting a possessive suffix to salvage the construction is also disallowed (*meniy Rembrandt-tuy suret-m

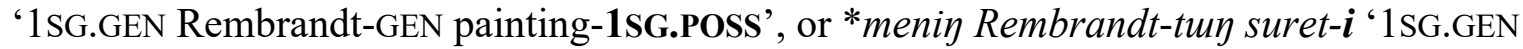
Rembrandt-GEN painting-3POSS'). ${ }^{14}$

(10) * menin Rembrandt-tun suret-i-m I.GEN Rembrandt-GEN painting-3POSS-1 SG.POSS Intended: 'the Rembrandt painting of mine'

\footnotetext{
${ }^{13}$ Double possessor constructions are disallowed irrespective of the person and number features of the possessors. For instance, two $3^{\text {rd }}$ person possessors (*onuy Rembrandt-tum suret-i-si '3SG/PL.GEN R.-GEN paining-3POSS3 POSS'), or one $2^{\text {nd }}$ and one $3^{\text {rd }}$ person possessor (*senin Rembrandt-tum suret-i- $\eta$ '2SG.GEN R.-GEN paining-3POSS2SG.POSS'), etc. would also be ungrammatical.

${ }^{14}$ At least, in this type of possessive construction. For a "special" usage (sometimes called "stylistic deletion" (Göksel \& Kerslake 2005: 163)) where the possessive suffix can be omitted see 3.2.
} 
The two approaches only differ in the position they would put the genitive RC subject, but the reason for the ungrammaticality of (7) is the same: two morphemes of the same type (possessive agreement) follow each other, and the deletion of possessive suffixes is disallowed. ${ }^{15}$

The purpose of this subsection is to show that even though the GEN-subject strategy cannot co-occur with a possessor, it does not (necessarily) argue in favor of the GEN-DP as possessor analysis, as the "GEN-DP inside the RC" approach could invoke the Stuttering Prohibition to account for the ungrammaticality of (7).

3.2 PROPER NOUNS MODIFIED BY RCS. A more convincing argument against the GEN-DP inside the RC approach comes from proper nouns modified by RCs. A person's name, such as Gülmira in (11), or 'the (unique) Sun', in (13), can be modified by a NOM-subject RC but not by a GENsubject RC, as illustrated by the infelicitous (12) and (14).

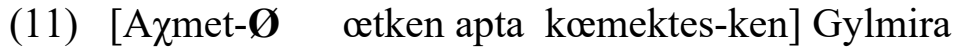
[Ahmet-NOM last week help-NF] Gülmira 'Gülmira(,) whom Ahmet helped last week'

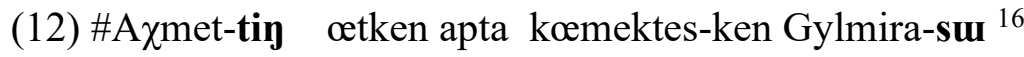
Ahmet-GEN last week help-NF Gülmira-3POSS Intended: 'Gülmira(,) whom Ahmet helped last week' 17

(13) [Yalum-dar-Ø zertte-p zat-kan] Kyn [scientist-PL-NOM study-IP AUX-NF] Sun 'the Sun, which the scientists are studying'

(14) \#Yalum-dar-dun zertte-p zat-kan Kyn-i scientist-PL-GEN study-IP AUX-NF Sun-3POSS 'the Sun, which the scientists are studying'

The unacceptability in (12) and (14) does not arise because of a potential restriction on the GEN-subject strategy in non-restrictive relative clauses. The following two examples illustrate this point. In (15), Saule owns three cars and the addressee saw only one of them. The relative clause 'which you saw yesterday' is restrictive in this context, and the GEN-subject strategy can be used. In (16), on the other hand, Saule only owns one car, and the relative clause 'which you saw yesterday' is used non-restrictively. Still, the GEN-subject strategy can be used in the nonrestrictive relative clause. If the restriction on the GEN-subject strategy was related to nonrestrictive RCs, we would expect (16) to be ungrammatical in the given context, contrary to fact.

(15) Context: You and I are chatting about Saule's cars. Saule has three cars, and we both know that you saw one of them yesterday. We both know which car you saw. I say to you:

Kefe senin kœr-gen mafina-n œete kumbat.

\footnotetext{
${ }^{15}$ Another possible explanation for the ungrammaticality of (6) is that both genitive-marked noun phrases are possessors and there is a ban against multiple specifiers in the DP. Thus, two possessors compete for one Spec,DP position, which I assume where possessors are, resulting in ungrammaticality. This analysis is only compatible with the analysis that puts the genitive-marked RC subject in the possessor position, but not with the "GEN-DP inside the RC" approach.

${ }^{16}$ I will consider this construction infelicitous and not ungrammatical, as pragmatic factors can improve its acceptability.

${ }^{17}$ A few consultants indicated that this might be acceptable under the reading that there is some sort of romantic involvement between Ahmet and Gülmira. This is, however, not the reading we are interested in here.
} 
yesterday you.GEN see-NF car-2SG.POSS very expensive

'The car that you saw yesterday is very expensive.'

(16) Context: You and I are chatting about Saule's car. Saule has only one car, and we both know that you saw it yesterday. I say to you:

Kefe senin kœr-gen mafina- $\boldsymbol{\eta}$ œte kumbat. yesterday you.GEN see-NF car-2SG.POSS very expensive

'The car, which you saw yesterday, is very expensive.'

This indicates that the unacceptability of (12) and (14) is not due to a restriction on the GENsubject strategy in non-restrictive RCs. Thus, the question arises: why are GEN-subject RCs in (12) and (14) degraded?

I submit that the reason why (12) and (14) are unacceptable is the same reason why the possessive constructions in (17) and (18) are unacceptable, namely that proper names cannot be possessed. (17) can only be used felicitously if there is some romantic connection between Ahmet and Gülmira. Notice that the same interpretation is available for the GEN-subject RC in (12), and only under that interpretation is the RC construction felicitous. If the only connection between Ahmet and Gülmira is that Ahmet helped Gülmira, neither (12), nor (17) are acceptable. Similarly, the possessive construction in (18), where 'the scientists' is the possessor of the individual-denoting term 'Sun', is not felicitous. This directly parallels the unacceptability of the GEN-subject RC in (14).

(17) \#A xmet-tin Gylmira-su Ahmet-GEN Gülmira-3POSS Intended: 'Ahmet's Gülmira'

(18) \#Valum-dar-dun Kyn-i scientist-PL-GEN Sun-3POsS Intended: 'the scientists' Sun'

The parallelism between the conditions on unacceptability of genitive possessor and genitive $\mathrm{RC}$ subjects supports the claim that the genitive $\mathrm{RC}$ subject is situated in the possessor position.

3.3 GENITIVE WITHOUT POSSESSIVE MARKING. There are two types of possessive constructions in Kazakh: the first type is when the possessor is marked with genitive and the possessee with possessive suffixes (see (19)), the second type is when the possessor is marked with the genitive and there is no possessive marking on the possessee, as in (20). The latter type is also known as "possessive-free genitives."

(19) biz-din Kazakstan-umuz we-GEN Kazakhstan-1PL.POSS 'our Kazakhstan'

(20) biz-din Kazakstan we-GEN Kazakhstan 'our Kazakhstan' 
Speakers report some slight difference in meaning between the two types, but more research is needed to determine the difference between these constructions. ${ }^{18}$ While the second, possessive-less, type is not as well understood as the type with the possessive suffix, there are some crucial differences between them reported in the literature for Turkish. Firstly, the possessive-less strategy cannot be used if the possessee is an inherently relational noun (for instance, a kinship term) (Öztürk \& Erguvanlı Taylan 2016: 92). Secondly, the possessive suffix has to be overt if the possessor is indefinite, an NP modified by a RC, or if it includes a quantifier (Özyıldız 2018). Öztürk \& Erguvanlı Taylan (2016: 94-95) also argue that the possessive-less constructions can only be used if the relation between the possessor and the possessum is in the common ground, they call this "presuppositional contexts."

The exact analysis of these two types of possessives is beyond the scope of this paper. In a nutshell, the possessive-less type is much less studied than the possessive-less type. In one line of approaches, possessive-less constructions are described as colloquial, and they are assumed to be the result of stylistic deletion (e.g., Göksel \& Kerslake 2005: 163). In contrast, Öztürk \& Erguvanlı Taylan (2016) show that there are interpretational differences between the two possessive types, which they explain by different syntactic representations. They argue that possessive suffixes realize the little $\mathrm{n}$ head, which introduces a nominal argument in its Specifier. Then the nominal argument moves to Spec,DP, where it gets genitive case. In possessive-less constructions, there is no little $\mathrm{n}$ projection, and the possessor is base-generated in Spec,DP. ${ }^{19}$ For the purposes of this paper it is not crucial to decide which one of these approaches is correct, rather I will focus on the differences between possessive marking in nominalized clauses and possessive constructions.

In nominalized clauses, only the first type is available, that is, the possessive suffix has to be overtly marked, as illustrated by the following nominalized complement clause. ${ }^{20}$ In (21), the subject is genitive marked and the subject agreement is indicated by the possessive suffix on the nominalized non-finite predicate. As sentence (22) shows, leaving out the agreement suffix

\footnotetext{
${ }^{18}$ In this specific example, speakers reported that when the possessive suffix is present, an emotional attachment to Kazakhstan is expressed. There is no such shade of meaning in the possessive-less construction.

${ }^{19} \mathrm{I}$ believe the possessive omission has not been investigated from the point of view of the Stuttering Prohibition, and it might pose a problem for this line of analysis.

The Stuttering Prohibition bans two consecutive morphemes of the same category to explain the ban against double possessor constructions. The Stuttering Prohibition would predict that one could combine an omitted possessive (i.e., possessive free construction) and a regular possessive into a double possessor construction. This is however not what we see. The omitted possessive construction in (i) cannot combine with a regular possessive, shown in the ungrammatical (ii).
}

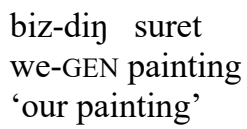

The ungrammaticality of (ii) suggests that problem with double-possessor construction is not the double possessive agreement marking but that Kazakh (and other Turkic languages, too, such as Turkish) only allows one specifier in the DP.

${ }^{20}$ On the face of it, the nominalized complement clause predicate looks the same as the not nominalized RC predicate. This is only apparent though. Ótott-Kovács (2015) and Ótott-Kovács (2018) show that the suffix -LIQ can follow the non-finite aspectual head $-G A n$ or $-y / A t I n$ in complement clauses but not in RCs. The $-L I Q$ morpheme is identified as a nominalizer that is optionally marked. 
results in ungrammaticality. This holds to all nominalized non-finite clause types. That is, possessive-free genitives seem to be only available for GEN-DP in possessor position but not for GEN-DP in non-finite clause subject position. ${ }^{21}$

(21) Ajnur-duin sunuptas-tar-u Aynur-GEN classmate-PL-3POSS

[onuy mektep-te zaksu oku-gan-un] ajt-tur.

[3.GEN school-LOC good study-NF-3POSS].ACC say-3PST

'Aynur's classmates said that she studied well in school.'

(22) *Ajnur-dury sunuptas-tar-u

Aynur-GEN classmate-PL-3POSS

[onuy mektep-te zaksu oku-gan]-nu ajt-tur.

[3.GEN school-LOC good study-NF]-ACC say-3PST

Intended: 'Aynur's classmates said that she studied well in school.'

In contrast to nominalized clauses, in RCs both possessive marking patterns are available. In (23), the subject is genitive, and the agreement is marked on the modified noun. In (24) the subject is genitive, and there is no agreement marked with it. All consultants reported the same difference in meaning between these two relative clauses as described above for possessive constructions: when the possessive is overt, there is an emotional attachment between the genitive-marked 'we' and the possessive-marked 'Kazakhstan'.

Biz-din dynje-ge kel-geli tur-gan Kazakstan-umuz-da we-GEN world-DAT come-since live-NF K.- 1PL.POSS -LOC zana oblus pajda bol-dur. new oblast' appear-3PST

'A new oblast' was established in the Kazakhstan where we've been living since we were born.' (emotional attachment between the subject and Kazakhstan)

(24) Biz-din dynje-ge kel-geli tur-gan Kazakstan-da zaya oblus pajda bol-dur. we-GEN world-DAT come-since live-NF K.-LOC new oblast' appear-3PST

'A new oblast' was established in the Kazakhstan where we've been living since we were born.'

(24) clearly shows that RCs with genitive-marked subjects pattern with possessive constructions, while nominalized clauses, such as (22), do not. This indicates that the genitivemarked DP can be in possessor position with a co-indexed pro/PRO subject in the RC subject position.

Note that these data is not incompatible with the "GEN-DP inside the RC" approach, as it would claim that the genitive-DP may also be in the possessor position.

3.4 RELATIONAL NOUNS MODIFIED BY RCS. Inherently relational nouns such as father, mother, president, etc. require a nominal argument (cf. e.g., Partee \& Borschev 2000). In Kazakh, if the modified noun phrase is a relational noun, the genitive DP is interpreted as the argument of the relational noun.

${ }^{21}$ The genitive-DP (onuy 'his/her') in (21) is inside the complement clause (i.e., it is not raised to a higher domain); the genitive case on this DP originates from the nominal projection that attaches to the verbal projections (possibly AspP) of the clause. 
Consider the following two sentences. In (25) the RC modifying the relational noun ceke 'father' has a nominative subject, and the sentence is felicitous, because the RC subject is not interpreted as the possessor of the modified NP 'father'. ${ }^{22}$ In contrast, in (26) the genitive subject must be interpreted as the possessor of the relational noun 'father', i.e., 'Saule's father', which results in infelicity, since the matrix clause states that the relevant father is Aynur's father, and a contradiction arises between Saule's father being the same person as Aynur's father (assuming that Saule and Aynur are not sisters).

[Sæule- Øe ke-gi toj-da uzak sœjles-ken] æke -

[Saule-NOM yesterday-ADJ celebration-LOC long chat-NF] father

Ajnur-dur æke-si.

Aynur-GEN father-3POSS

'The father with whom Saule chatted for a long time at the celebration yesterday is Aynur's father.'

(26) \#Sæule-nin ke e-gi toj-da uzak sœjles-ken æke-si -

Saule-GEN yesterday-ADJ celebration-LOC long chat-NF father-3POSS

Ajnur-dun rke-si.

Aynur-GEN father-3POSS

Intended: 'The father with whom Saule chatted for a long time at the celebration yesterday is Aynur's father.'

(26) clearly shows that the genitive-DP can - or as I argue, must - be in the possessor position. The GEN-DP inside the RC account, which would maintain that the genitive-subject in (26) is inside the RC and not in the possessor position, would predict that (26) could be felicitous, contrary to the fact.

Nevertheless, I do not think that this is the strongest argument against the GEN-DP inside the $\mathrm{RC}$ approach. While proponents of the GEN-DP inside the RC approach have not discussed examples similar to (26), one can imagine a bias for interpreting the genitive-DP in the possessor position over the RC subject position when the target noun phrase requires a DP argument.

3.5 NPI SUBJECTS IN RELATIVE CLAUSES. In this section, I focus on Negative Polarity Item (henceforth, NPI) licensing in RC subject position. NPIs are words that may occur in domains that are "in some sense negative," such as negation, interrogatives and downward entailing contexts (for a summary on NPIs see e.g., Penka \& Zeijlstra 2010, Giannakidou 2011). In Kazakh, unlike in English, NPIs can be licensed in subject position, illustrated in (27), where the NPI efkim is the subject of the sentence. The ill-formed (28) shows that efkim does not express negation on its own, it needs to be licensed by a domain-internal NPI-licensor.

Ejkim zumus iste-me-jdi.

anyone work do-NEG-3PRS

'No one works.'

(28) *EJkim zumus iste-jdi.

anyone work do-3PRS

Intended: 'No one works.'

\footnotetext{
${ }^{22}$ I offered the following context for these two sentences: "there was an event for fathers, where there were lots of fathers present; the next day I am chatting with a friend about the event." This context is followed by sentences (25) and (26).
} 
NPIs can also be licensed in the possessor position (as in (29)) and in the subject position of a nominalized clause (see (30)) by matrix negation. NPI licensing is expected to take place within a phase, but in accordance Chomsky's Phase Impenetrability Condition (Chomsky 1998, 2001), phase-edges are accessible for outside probes. The possessor in (29) and the genitivemarked subject of the nominalized clause in (30) are at the left-edge of their respective phases, thus accessible for NPI licensing to matrix licensors. ${ }^{23}$

$$
\begin{array}{ll}
\text { [EJkim-nin } \text { œlen-i] magan una-ma-dur. } \\
\text { [anyone-GEN poem-3POSS] I.DAT like-NEG-3PST }
\end{array}
$$

'I didn't like anyone's poem.'

(30) [EJkim-niך zumus iste-gen-in] kœr-gen zok.

[anyone-GEN work do-NF-3POSS].ACC see-PRF NEG

'S/he did not see anyone working.'

Turning to RCs, the two approaches have different predictions with respect to NPI licensing in the RC subject position. Both approaches predict that matrix negation can license NPI if the RC subject is genitive-marked. For the GEN-DP inside the RC approach, the NPI can be licensed in the RC-internal left edge position, similarly to NPI licensing in (30). For genitive-DP-aspossessor approach, NPIs are allowed to be licensed because the GEN-DP is in possessor position, just as we saw in (29). This prediction is indeed borne out, GEN-NPI subject can be licensed by matrix negation, as shown in (31).

Ke ee efkim-nin ajt-kan olen-i magan una-ma-dur.
yesterday anyone-GEN say-NF poem-3POSS I.DAT like-NEG-3PST
'I didn't like the poem that someone told us yesterday.'

Since both approaches would place the NOM-RC subject in a lower, not edge, position, they would predict that NOM-NPI RC subjects cannot be licensed by matrix negation, which is indeed what I found.

(32) *[Kefe efkim-Ø ajt-kan] œlen magan una-ma-du. [yesterday anyone-NOM say-NF] poem I.DAT like-NEG-3PST 'I didn't like the poem that someone told us yesterday.'

However, the analyses differ in their predictions about NPI licensing with RC-internal negation. These analyses, naturally, predict the availability of NOM-NPI subjects under RCinternal negation. The contrast emerges when it comes to GEN-DPs. The GEN-DP inside the RC approach maintains that the GEN-DP is clause-internal, therefore it predicts that GEN-NPI subject can be licensed under RC-internal negation the same way as NOM-subjects. In contrast, the GENDP as possessor approach claims that the GEN-DP is clause-external, therefore we do not expect NPI licensing taking place under RC-internal negation.

I found that speakers uniformly accept NOM-NPI subjects, shown in (33), as predicted by both approaches.

(33) [Bul kala-da efkim-Ø tanu-ma-jtun] mugalum-du [this city-LOC anyone-NOM know-NEG-NF] teacher-ACC kalaj tab-a-muz?

\footnotetext{
${ }^{23}$ None of this is surprising. other Turkic languages, e.g., Turkish, show the same NPI-licensing patterns (Yanilmaz \& Drury 2018).
} 
how find-PRS-PL1

'How are we going to find a teacher whom no one knows in this city.'

I did not find the same uniformity in judgements with GEN-DPs. While the judgements are somewhat mixed, more consultants found the GEN-NPI under RC-internal negation ungrammatical than grammatical, shown in (34). When the GEN-NPI and the negative RC predicate were not string-adjacent, this distinction was even greater, shown in (35). ${ }^{24}$

(34)??Bul kala-da efkim-nin tanu-ma-jtun mugalum-un

this city-LOC anyone-GEN know-NEG-NF teacher-3POSS.ACC

kalaj tab-a-muz? $\left(4^{*}, 3 \checkmark\right)$

how find-PRS-PL1

Intended: 'How are we going to find a teacher whom no one knows in this city.'

(35) *EJkim-nin bul kala-da tanu-ma-jtum mugalum-un anyone-GEN this city-LOC know-NEG-NF teacher-3POSS.ACC

kalaj tab-a-muz? $\left(5^{*}, 2 \sqrt{ }\right)$

how find-PRS-PL1

Intended: 'How are we going to find a teacher whom no one knows in this city.'

(34) and (35) are not expected under the GEN-DP inside the RC approach, as it would predict the same acceptability of GEN-NPI RC subjects as of nominative ones (as in (33)). Rather, the Kazakh NPI facts lend support the GEN-DP-as possessor approach, which predicts the unavailability of GEN-NPI RC subjects under RC-internal negation. ${ }^{25}$ Table 1 provides a summary of the predictions made by the two approaches, and the results of the grammaticality judgement task (in the Findings column). The Kazakh NPI facts support the GEN-DP-as possessor analysis.

\footnotetext{
${ }^{24}$ Note that the same word order with NOM-NPI subject is only marginally acceptable, shown in (i). I assume that the reason for this is different than the ill-formedness of the GEN-NPI in (35). Since NOM-RC subjects are in a lower position, many consultants prefer to place the adverb in a higher position, unless some information structural reason requires the adverb to be fronted.

(i) ? [Ejkim-Ø bul kala-da tanu-ma-jtun] mugalum-du [anyone-NOM this city-LOC know-NEG-NF] teacher-ACC

kalaj tab-a-muz? $\left(3^{*}, 4 \sqrt{ }\right)$

how find-PRS-PL1

'How are we going to find a teacher whom no one knows in this city.'

${ }^{25}$ It requires more research why a small minority of speakers did accept GEN-NPI DPs. It could simply be a shortcoming of the grammaticality judgement task, and indeed, some consultants found the judgements with NPIs more difficult than in other sentences. Or these speakers might have different grammars than the majority of speakers; this grammar could be different in terms of NPI-licensing or in terms of the position of the GEN-DP.
} 


\begin{tabular}{lllll} 
& & $\begin{array}{l}\text { GEN-DP inside } \\
\text { the RC }\end{array}$ & $\begin{array}{l}\text { GEN-DP-as } \\
\text { possessor }\end{array}$ & FINDINGS \\
\hline Matrix negation & NOM-subject & $*$ & $*$ & $*$ \\
& GEN-subject & $\checkmark$ & $\checkmark$ & $\checkmark$ \\
\hline Negation in the & NOM-subject & $\checkmark$ & $\checkmark$ & $\checkmark$ \\
RC & GEN-subject & $\checkmark$ & $*$ & $? ? / *$
\end{tabular}

Table 1: Predictions by the two analyses, and findings based on Kazakh data

4. Conclusions and further directions. In sections 3.2-3.4, I showed that the GEN-RC subject patterns with possessors and not with complement clause GEN-subjects. Crucially, the approach that assumes that the GEN-DP is RC-internal cannot explain the restriction on GEN-marking when the noun phrase modified by the $\mathrm{RC}$ is a proper name. In contrast, it is easily explainable under the analysis that maintains that the GEN-DP is in the possessor position. Furthermore, the NPI data indicate that the GEN-DP is not RC-internal, because RC-internal negation cannot (or only marginally, for some speakers) license a GEN-NPI RC subject.

Based on the novel Kazakh data, I conclude that the GEN-DP is in the possessor position (see the tree representation in (36)). I also assume there is a pro or PRO coindexed with the possessor in the Spec,IP position of the relative clause. The choice between these depends on where the GEN-DP originates: if the GEN-DP is base-generated in the possessor position, the pro subject is expected to be in Spec,IP. ${ }^{26}$ If this is the case, it is also expected that, under contextual support, the GEN-DP and RC subject can have disjoint reference. On the other hand, if the GEN-DP originates in Spec,IP, and is moved to Spec,DP, the subject of the RC is PRO, obligatorily coreferent with the DP in possessor position. Some of preliminary results indicate that the first approach might be on the right track for Kazakh, but more research is needed to draw final conclusions.

(36) Proposed syntactic structure for the GEN-subject strategy

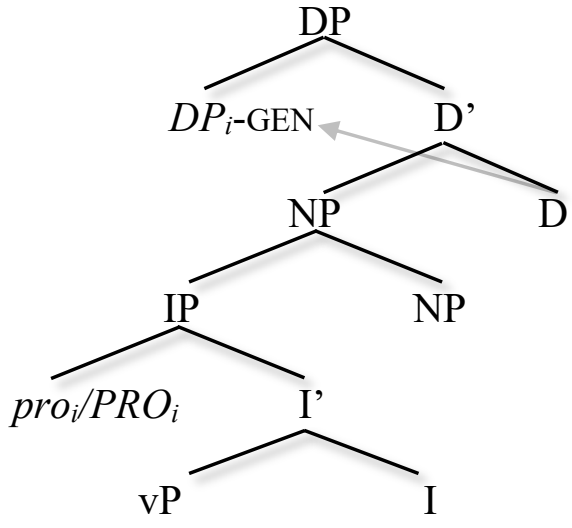

\footnotetext{
${ }^{26}$ One of the reviewers asks why I think base-generation in possessor position is a possible analysis, and not posit movement from Spec,IP to the possessor position, as Satık (2020) does. While I do not think that there is a definitive answer to this question, I do find movement out of a RC, which is an adjunct, into the possessor position theoretically (and empirically) problematic. It is well-established in the literature that RCs are islands for movement. As far as I see, we do not have any decisive evidence for movement, and because positing it would be theoretically controversial, it seems reasonable to maintain at least the possibility of the base-generation in possessor position analysis.
} 
I should also note that being in the possessor position does not necessarily indicate an ownership or authorship relation to the possessee. That is, being in the possessor position does not mean that the GEN-DP is necessarily the possessee's owner or author. Rather, following Partee \& Borschev (2000), Vinkner \& Jensen (2002), I take the relation between possessor and possessee a pragmatically controlled relation, where the context provides the exact nature of the relation between these DPs. In the Kazakh case, this relation is overtly provided by the RC.

While this article offered new data supporting that the GEN-DP is in the RC-external possessor position, there are other relevant issues, such as adverb placement facts in the case of the GEN-subject strategy (first noticed by Kornfilt 2008), are beyond the scope of this article. These will be dealt with in a future article.

\section{References}

Asarina, Alevtina (Alya). 2010. Case in Uyghur and Beyond. Cambridge, MA: MIT PhD Dissertation. http://web.mit.edu/alya/www/asarina thesis.pdf

Baker, Mark \& Nadya Vinokurova. 2010. Two modalities of case assignment: Case in Sakha. Natural Language and Linguistic Theory (28). 593-642. https://doi.org/10.1007/s11049-010-9105-1

Chomsky, Noam. 1998. Minimalist inquiries: The framework. MIT Working Papers in Linguistics. Cambridge, MA: MIT Press.

Chomsky, Noam. 2001. Derivation by Phase. In M. Kenstowicz (ed.) Ken Hale: A Life in Language. 1-52. Cambridge, MA: MIT Press. https://doi.org/10.7551/mitpress/4056.001.0001

Csató, Éva \& Muzappar Abdurusul Uchturpani. 2010. On Uyghur relative clauses. Turkic Languages 14. 69-93.

Giannakidou, Anastasia. 2011. Positive polarity items and negative polarity items: Variation, licensing, and compositionality. In C. Maienborn, K. von Heusinger, \& P. Portner (eds.) Semantics: An international handbook of natural language meaning. 1660-1712. Berlin: Mouton de Gruyter. https://doi.org/10.1515/9783110255072.1660

Göksel, Aslı \& Celia Kerslake. 2005. Turkish: A Comprehensive grammar. London/New York: Routledge.

Hale, Ken. 2002. On the Dagur Object Relative: Some Comparative Notes. Journal of East Asian Linguistics 11(2). 109-122.

Kornfilt, Jaklin. 1986. The Stuttering Prohibition and morpheme deletion in Turkish. In A. Aksu Koç \& E. Erguvanlı Taylan (eds.) Proceedings of the Second Conference in Turkish Linguistics. 59-83. Istanbul: Boğaziçi University Publications.

Kornfilt, Jaklin. 2005. Agreement and its placement in Turkic nonsubject relative clauses. In Cinque G. \& S. Kayne (eds.) The Oxford Handbook of Comparative Syntax. 513-541. Oxford/New York: Oxford University Press. https://doi.org/10.1093/oxfordhb/9780195136517.013.0012

Kornfilt, Jaklin. 2008. Subject Case and Agr in two types of Turkic RCs. In S. Ulutaş \& C. Boeckx (eds.) Proceedings of WAFL 4. 145-168. Cambridge, MA: MITWPL 56.

https://www.eva.mpg.de/lingua/conference/08_springschool/pdf/course_materials/Kornfilt RC_hdt1.pdf

Kornfilt, Jaklin. 2009. A constraint on certain relative clauses in Turkic. In E. Y1lmaz, S. Eker \& N. Demir (eds.) Festschrift for Talat Tekin. Special issue. International Journal of Central 
Asian Studies. 373-398. Seoul: The International Association of Central Asian Studies, Korea University of International Studies.

Kornfilt, Jaklin. 2015. Turkish Relative Clauses: How Exceptional are they from a Central Asian Turkic Perspective? https://pdfs.semanticscholar.org/d1e9/ec15a996b94a22e8e1a72b44f66e3125de2b.pdf

Laszakovits, Sabine. 2018. On possessed relative clauses in Kyrgyz. Handout presented at WAFL14, MIT. Oct. 19. 2018.

https://www.researchgate.net/publication/328812451_On_possessed_relative_clauses_in_ Kyrgyz

Laszakovits, Sabine. 2019a. On possessed relative clauses in Kyrgyz. In T. Bondarenko, C. Davis, J. Colley \& D. Privoznov (eds.) Proceedings of the 14th Workshop on Altaic Formal Linguistics (WAFL14): MITWPL 90. Cambridge, MA. 157-168.

Laszakovits, Sabine. 2019b. Kyrgyz Relative Clauses and Dependent Case Theory. Handout presented at $\mathrm{Tu}+4$ at NYU. Feb. 17. 2019.

Ótott-Kovács, Eszter. 2015. The Syntax of non-finite clauses in Kazakh. Szeged: University of Szeged PhD Dissertation. https://doi.org/10.14232/phd.2934

Ótott-Kovács, Eszter. 2018. Kazakh non-finite clauses followed by $-L I Q$ as a case in favor of the clause-internal nominalization hypothesis. Y. Köylü and J. Kornfilt (eds.), Papers in Turkish and Turkic Linguistics. Proceedings of The Second Workshop on Turkish, Turkic, and the Languages of Turkey: Tu+ 2. Bloomington, Indiana: Indiana University Linguistics Club Working Papers.

Öztürk, Balk1z. 2005. Case, Referentiality and Phrase Structure. Amsterdam: John Benjamins. https://doi.org/10.1075/la.77

Öztürk, Balkız \& Eser Erguvanlı Taylan. 2016. Possessive constructions in Turkish. Lingua 182. 88-108. https://doi.org/10.1016/j.lingua.2015.08.008

Özyıldız, Deniz. 2018. Not All Possessors in Turkish are Anti-Subject Oriented. In Workshop on Altaic Formal Linguistics 10. http://deniz.fr/pdfs/possessives_paper.pdf

Partee, Barbara H. \& Vladimir Borschev 2000. Possessives, favorite, and coercion. In A. Riehl \& R. Daly (eds.) Proceedings of ESCOL99. 173-190. Ithaca, NY: CLC Publications, Cornell University.

Penka, Doris \& Hadde Zeijlstra. 2010. Negation and polarity: An introduction. Natural Language \& Linguistic Theory 28(4). 771- 786. https://doi.org/10.1007/s11049-010-9114-0

Satık, Deniz 2020. Turkic genitive case and agreement asymmetries. Manuscript. https://ling.auf.net/lingbuzz/004981

Tat, Deniz \& Jaklin Kornfilt. 2018. Haplology within M-Words and P-Words: Revisiting the Stuttering Prohibition in Turkish. In Y. Köylü and J. Kornfilt (eds.), Papers in Turkish and Turkic Linguistics. Proceedings of The Second Workshop on Turkish, Turkic, and the Languages of Turkey: Tu+2. Bloomington, Indiana: Indiana University Linguistics Club Working Papers. https://openaccess.leidenuniv.nl/handle/1887/58546

Vikner, Carl \& Per Anker Jensen. 2002. A semantic analysis of the English genitive: Interaction of lexical and formal semantics. Studia Linguistica 56(2). 191-226. https://doi.org/10.1111/1467-9582.00092

Yanilmaz, Aydogan \& John E. Drury. 2018. Prospective NPI licensing and intrusion in Turkish. Language, Cognition and Neuroscience 33(1). 111-138.

https://doi.org/10.1080/23273798.2017.1371779 